\title{
Alfabetização e letramento na escola do campo: um estudo em turmas de EJA na Escola Santo Antônio, Rio Bacuri, Abaetetuba, Pará
}

\author{
Literacy and lettering in the rural school: a study in EJA classes at Escola Santo Antônio, Rio \\ Bacuri, Abaetetuba, Pará \\ Alfabetización y letramento en la escuela rural: un estudio en las clases de EJA en la Escola Santo \\ Antônio, Rio Bacuri, Abaetetuba, Pará
}

Recebido: 09/08/2021 | Revisado: 15/08/2021 | Aceito: 16/08/2021 | Publicado: 19/08/2021

\author{
Marcos José Silva Maués \\ ORCID: https://orcid.org/0000-0001-6036-8091 \\ Secretaria Municipal de Educação de Abaetetuba, Brasil \\ E-mail: djmarquinhosata@hotmail.com \\ Pedro Chaves Baia Junior \\ ORCID: https://orcid.org/0000-0002-3937-0776 \\ Instituto Federal de Educação, Ciência e Tecnologia do Pará, Brasil \\ E-mail: pedro.baiajr@ifpa.edu.br
}

\begin{abstract}
Resumo
Alfabetizar jovens e adultos em escolas localizadas em áreas rurais é um dos desafios enfrentados pelos professores, os quais, em geral, não possuem formação específica (graduação ou especialização na área) para auxiliá-los em suas práticas de sala de aula com esse público característico de alunos. Diante disso, o presente artigo tem como objetivo investigar as práticas pedagógicas de alfabetização de jovens e adultos adotadas na Escola Municipal Santo Antônio, localizada no Rio Bacuri, região das ilhas de Abaetetuba, Pará. Como metodologia optaremos pela pesquisa qualitativa e entrevista com um professor da Educação de Jovens e Adultos (EJA) e a diretora da instituição de ensino pesquisada. Com base nas entrevistas evidenciou-se que o processo de alfabetizar na Escola Municipal Santo Antônio enfrenta vários desafios que vão desde os horários das aulas, que não correspondem com a disponibilidade dos alunos, até a falta de espaço para o desenvolvimento das aulas, bem como a falta de profissionais, como coordenação pedagógica e serventes. Isso faz com que o professor da EJA trabalhe sozinho, assumindo todas as tarefas necessárias para o funcionamento do espaço escolar. Ademais, identificou-se que, apesar dos desafios enfrentados, o professor cria e desenvolve diferentes estratégias que se aproximam do letramento para diversificar o trabalho docente, contribuindo com o processo de ensino e aprendizagem dos alunos da EJA.
\end{abstract}

Palavras-chave: Comunidades ribeirinhas; Ensino-aprendizagem; Formação específica.

\begin{abstract}
Literacy for young people and adults in schools located in rural areas is one of the challenges faced by teachers, who, in general, do not have specific training (graduation or specialization in the area) that can help them in their classroom practices with this audience. specific. Therefore, this article aims to investigate the pedagogical practices of youth and adult literacy adopted at the Santo Antônio Municipal School, located on the Bacurí River, region of the islands, in Abaetetuba, Pará. As a methodology, we will choose qualitative research and interview with a teacher of Youth and Adult Education and the principal of the researched school. Based on the interviews, it was evident that the literacy process at the Santo Antônio Municipal School faces several challenges ranging from class schedules that do not correspond to the availability of students, the lack of space for the development of classes, as well as the lack of professionals such as pedagogical coordination and servants, making the EJA teacher work alone, assuming all the tasks necessary for the functioning of the school space. Furthermore, it was identified that, despite the challenges faced, the teacher creates and develops different strategies that approach literacy to diversify their work, contributing to the teaching and learning process of EJA students.
\end{abstract}

Keywords: Riverside communities; Teaching-learning process; Specific training.

\section{Resumen}

La alfabetización de jóvenes y adultos en escuelas ubicadas en zonas rurales es uno de los desafíos que enfrentan los docentes, quienes, en general, no cuentan con una formación específica (graduación o especialización en el área) que les pueda ayudar en sus prácticas de aula con esta audiencia. Por lo tanto, este artículo tiene como objetivo investigar las prácticas pedagógicas de alfabetización de jóvenes y adultos adoptadas en la Escuela Municipal Santo Antônio, ubicada en el río Bacurí, región de las islas, en Abaetetuba, Pará. Como metodología, optaremos por investigación 
cualitativa y entrevista con un profesor de Educación de Jóvenes y Adultos y el director de la escuela investigada. A partir de las entrevistas, se evidenció que el proceso de alfabetización en la Escuela Municipal Santo Antônio enfrenta varios desafíos que van desde horarios de clases que no se corresponden con la disponibilidad de los estudiantes, la falta de espacio para el desarrollo de las clases, así como la falta de de profesionales como la coordinación pedagógica y los servidores, haciendo que el docente de EJA trabaje solo, asumiendo todas las tareas necesarias para el funcionamiento del espacio escolar. Además, se identificó que, a pesar de los desafíos enfrentados, el docente crea y desarrolla diferentes estrategias que abordan la alfabetización para diversificar su trabajo, contribuyendo al proceso de enseñanza y aprendizaje de los estudiantes de EJA.

Palabras clave: Comunidades rebereñas; Proceso de enseñanza-aprendizaje; Formación específica.

\section{Introdução}

O analfabetismo ainda é um desafio no cenário brasileiro, especialmente para as comunidades do campo. Pesquisas, como a de Braga e Mazzeu (2017), apontam que o número de analfabetos ainda é significativo quando se trata de adultos acima de 15 anos de idade que não sabem ler e escrever. Certamente, esse entrave ocasiona a exclusão social e a falta de capacitação profissional, entre outros problemas.

Esse número significativo de analfabetos pode estar relacionado a fatores, como: infraestrutura das escolas, a qual muitas vezes é precária e ausência de espaços para os alunos adultos; desigualdade etária, racial ou social, pois a maioria dos analfabetos possui mais de 60 anos e um índice considerado desse grupo identifica-se como preto ou pardo; e, modelos antigos de ensinar e aprender, sem adoção de metodologias específicas à realidade dos educandos, o que não permite a criatividade, o diálogo e principalmente a aprendizagem dos alunos, além de provocar insegurança, evasão escolar e insatisfação (Braga \& Mazzeu, 2017; Luz, et al., 2021).

Diante dessas evidências existem professores que ainda culpabilizam os alunos pela não aprendizagem. Alguns docentes relacionam a dificuldade de aprendizagem dos estudantes ao período que os alunos da Educação de Jovens e Adultos (EJA) ficaram sem estudar, tal como à idade adulta que não é apropriada para adquirir aprendizados e, ainda, à questão da conciliação dos estudos com o trabalho e à família, entre outros fatores. De acordo com Perrenoud (2000, p. 18), “[...] normalmente define-se o fracasso como a simples consequência de dificuldade de aprendizagem e como a expressão de uma falta 'objetiva' de conhecimento e competências por parte dos alunos", e essa concepção poderá ter "possibilidade de que não haja ascensão a partir dessa escolarização, mas sim que a classe seja reproduzida, ou seja, não avançam, a exemplo de conseguir profissionalização ou ascender academicamente (Santos \& Ribeiro, 2020, p.3)

Sendo assim, percebe-se o quanto é importante considerar alguns fatores como contribuintes para a eficácia do processo de ensino e aprendizagem da leitura e escrita dos alunos da EJA, principalmente o fator metodológico de ensino. Segundo o Minidicionário Houaiss (2004), este é definido “como um conjunto de métodos, regras e postulados utilizados em determinada disciplina e sua aplicação". A metodologia é, portanto, uma tomada de decisão que o docente se propõe a assumir para que o processo de ensino e aprendizagem se realize satisfatoriamente, pois com essa decisão tentará alcançar suas metas e seus anseios em relação à aprendizagem do educando.

Dentre muitos métodos de ensino para trabalhar com os jovens e adultos, Freire (1987) foi um dos autores que se preocupou com a educação da classe trabalhadora. Conforme o autor, a "leitura de mundo" precede a "leitura da palavra". Então, não há como desconsiderar as experiências de vida dos jovens e adultos no processo de alfabetização e letramento, buscando palavras geradoras a partir da realidade dos alunos.

Estas palavras são chamadas geradoras porque, através da combinação de seus elementos básicos, propiciam a formação de outras. Como palavras do universo vocabular do alfabetizando, são significações constituídas ou reconstituídas em comportamentos seus, que configuram situações existenciais ou, dentro delas, se configuram. Representativos das respectivas situações que, da experiência vivida do alfabetizando, passam para o mundo dos 
objetos. O alfabetizando ganha distância para ver sua experiência: "admirar". Nesse instante, começa a descodificar (Freire, 1987, p. 6).

Como se pode perceber esse método freireano é baseado em Palavras Geradoras, isto é, não se ensina a repetição de palavras, mas a desenvolver a capacidade de pensá-las com base nas palavras retirados do cotidiano dos alunos, formando, assim, as palavras geradoras que por meio de uma palavra conseguimos formar muitas outras diferentes. Essa maneira de efetivar o ensino torna-se muito mais fácil para o entendimento dos alunos (Freire, 1987).

Nesse contexto de garantir a democratização do ensino para todos e de prezar pela adoção de metodologias produtivas de aprendizagens, alfabetizar os alunos da EJA no processo de letramento é muito importante. Soares (2016) defende que o processo de alfabetização se relaciona com a apropriação da escrita: "alfabetizar significa adquirir a habilidade de decodificar a língua oral em língua escrita[...]. A alfabetização seria um processo de representação de fonemas em grafemas (escrever) e de grafemas em fonemas" (Soares, 2016, p. 15). Ainda para a autora, o letramento está relacionado com o processo de construção das habilidades de leitura e escrita nas práticas sociais, ou seja, em situações reais de comunicação.

A partir dessas considerações, o presente artigo tem como objetivo investigar as práticas pedagógicas de alfabetização de jovens e adultos adotadas na Escola Municipal Santo Antônio, localizada no Rio Bacuri, região das ilhas de Abaetetuba, Pará. O interesse por essa temática surge a partir da vivência do primeiro autor deste estudo nas ilhas, durante um período do “Curso de Especialização em Educação de Jovens e Adultos: saberes ribeirinhos e práticas pedagógicas”, realizado no Instituto Federal do Pará (IFPA) - Campus Abaetetuba.

Essa capacitação fundamenta-se, dentre outros elementos, no regime de alternância, que consiste na estruturação curricular fundada entre o Tempo-Espaço Escola-Curso (TE) e o Tempo-Espaço Comunidade-Escola do Campo (TC). O Tempo-Espaço Escola-Curso (TE) trata-se do “[...] tempo presencial em que os estudantes estão juntos na Universidade ou em outro local, onde se desenvolvem as aulas e orientações para trabalhos práticos nas comunidades de origem e para o desenvolvimento de todos os outros tempos educativos" (Almeida \& Antonio, 2008, p. 28). E o Tempo-Espaço ComunidadeEscola do Campo (TC)

[...] é o tempo em que os estudantes estão em suas comunidades, desenvolvendo suas práticas, bem como outras atividades do Curso, de estudo e pesquisa. Entendemos esse tempo tanto para trabalhos individuais de cada estudante, como tempo reservado para os coletivos regionais, com acompanhamento de assessoria pedagógica (Almeida \& Antonio, 2008, p. 28).

Em nossas vivências no Tempo Comunidade, que foram realizadas nas escolas localizadas em áreas rurais, foram relatados por algumas equipes gestora e de professores a dificuldade sobre o número considerado de alunos da EJA que não conseguem ler e escrever. Segundo eles, isso fica evidente principalmente na $1^{\circ}$ etapa $\left(1^{\circ}\right.$ e $2^{\circ}$ anos) e $2^{a}$ etapa ( $3^{\circ}$ e $4^{\circ}$ anos $)$ dessa modalidade de ensino, podendo ser conduzido à evasão e reprovação, as quais evidenciam o fracasso escolar.

Sabe-se que o fracasso escolar é reflexo de inúmeras problemáticas encontradas dentro e fora do espaço escolar. Esses entraves contribuem para que o aluno não consiga alcançar os conhecimentos necessários para a vida escolar e o âmbito profissional. Segundo Porcaro (2011, p. 41),

Os educadores da EJA enfrentam inúmeros desafios no desenvolvimento de sua prática docente, como a heterogeneidade, a evasão, a juvenilização das turmas, a falta de materiais didáticos específicos, a baixa autoestima dos educandos, a rigidez institucional. Porém, em todas as situações, esses educadores apontam que vão buscando caminhos alternativos que favoreçam o processo de ensino, como criações próprias de cada uma diante das circunstâncias que vão enfrentando.

Além desses desafios enfrentados pelo professor da EJA em sala de aula, existem outros, como: "a dificuldade dos 
alunos em frequentar a escola, em função da sua realidade diária - problemas com o trabalho, familiares e domésticos" (Porcaro, 2011, p. 41). Os desafios do processo de ensino e aprendizagem na Educação de Jovens e Adultos serão, portanto, abordados e exemplificados com maior profundidade a seguir.

\section{Educação de Jovens e Adultos: o Processo de Ensino-Aprendizagem e as Especificidades em Relação à Alfabetização}

Quando falamos em alfabetização automaticamente pensamos no ensino de crianças que ainda não conseguem ler e escrever, isto é, no processo de ensino e aprendizagem para crianças de 6 a 10 anos do Ensino Fundamental - Anos Iniciais. Entretanto, pensando para além, há um público específico que também necessita ser alfabetizado: trata-se de jovens e adultos que por diversos motivos não puderam concluir os estudos na idade correta.

A EJA faz parte da modalidade de ensino básico e está presente nas escolas para que os alunos que não puderam concluir seus estudos na idade correta sejam assistidos da devida maneira e assim possam concluir a Educação Básica. Ela também é garantida por lei e precisa ser cumprida dentro das escolas, conforme a Lei nº 9.394, de 1996, no Art. 37, parágrafo $1^{\circ}$ :

Os sistemas de ensino assegurarão gratuitamente aos jovens e aos adultos, que não puderem efetuar os estudos na idade regular, oportunidades educacionais apropriadas, consideradas as características do alunado, seus interesses, condições de vida e de trabalho, mediante cursos e exames. (Brasil, 1996, p. 30).

Nesse sentido, fica entendido que é obrigação das instituições públicas de ensino promoverem gratuitamente o ensino para jovens e adultos por meio da EJA, sempre adequando a metodologia de ensino ao público que está sendo atendido. Dessa maneira, garantir o direito à educação permite que o alunado crie interesse pelos estudos e tenha necessidade de escolarização. Dito isso, a educação de jovens e adultos favorece e promove a capacitação do aluno para o mundo e principalmente o prepara e o assegura na busca por melhoria de vida.

É necessário entendermos que a EJA atende uma parcela de estudantes que já está na vida adulta, ou seja, esses alunos já possuem vivência do mundo externo à escola, não se comparando com crianças na idade de alfabetização. Por esse motivo a EJA deve adotar processos de ensino e aprendizagem compatíveis com os discentes que buscam formação nessa modalidade de ensino.

Nesse prisma, o processo de alfabetização na EJA deve ser diferenciado do que é realizado nos anos iniciais do ensino regular, uma vez que se trata do ensino para adultos. Por isso, os métodos devem estar adequados para o público-alvo em questão. $\mathrm{O}$ ensinar ou o como ensinar precisa ser adaptado, portanto, à realidade dos jovens e adultos. Isso requer que o aluno se sinta confortável com o ambiente da sala de aula e que, acima de tudo, compreenda o que está sendo ensinado. Assim, traçar estratégias que visem o melhor desempenho do estudante fazem parte de um trabalho em conjunto, a ser desenvolvido pelo professor, pela escola e pelo próprio discente. Sendo assim, o trabalho articulado dessa tríade é o primeiro passo para uma educação de sucesso.

Além disso, sendo a educação o ponto principal na formação dos sujeitos como seres pensantes e aptos para a vida externa à escola, alfabetizar adultos requer atenção, dedicação e principalmente dinamismo, dado que os alunos têm acima de quinze anos. Então, o desafio do professor é sempre ter uma nova visão de alfabetização, pois a forma que ele escolherá para alfabetizar dirá se o feedback será positivo ou negativo, como afirma Dalbosco (2015, p. 6): "Através de estratégias aplica-se e expõem-se meios, métodos, formas e jeitos de ensinar visando evidenciar o pensamento, deixando claro o ponto que se deseja chegar, onde cabe de terminar a dinâmica mais adequada para se atingir o objetivo" 
O autor também evidencia de forma suscinta que por meio de estratégias diferenciadas o ensino traça um caminho onde o pensar age para que a aprendizagem seja dinâmica a fim de que o objetivo seja alcançado, o de alfabetizar o aluno adulto. Nesse processo de aprendizagem a metodologia do professor é parte fundamental, pois é a partir dela que o feedback do aluno acontecerá. A ação docente muitas vezes pode acarretar dificuldades e o método do professor é que irá ajudar a desfazer os bloqueios que podem surgir durante as aulas.

Isso significa que a alfabetização precisa ser ensinada e trabalhada na EJA de forma que insira o aluno na sala de aula. Assim, as práticas escolhidas muito ajudarão nesse processo, visto que atrair um estudante adulto para aprender a ler e escrever requer cuidados, pois ele pode se sentir acuado mediante o desafio da escolarização. Esse comportamento pode prejudicá-lo, levando-o à desistência e, consequente, à evasão escolar. Para que isso não aconteça, cabe ao professor adaptar seu método e, principalmente, à escola a tarefa de revisar o currículo, tornando-o mais adequado para o público da EJA.

Muitas teorias que abordam a alfabetização na educação de adultos, como a de Paulo Freire, auxiliam o docente no momento de trabalhar os conteúdos e de desenvolver as atividades, mas o desempenho do aluno depende dele e da colaboração do professor. Nesse ambiente de alfabetização, deve-se sempre considerar que o estudante da EJA almeja a formação escolar, portanto tomar como base teorias e práticas contundentes são questões-chave para alcançar um bom ensino.

Paulo Freire, em Educação e Mudança, analisava o processo de ensino e aprendizagem na EJA como libertador, ou seja, a educação era concretizada como prática de liberdade. Nessa perspectiva, o autor defende o ato de ensinar olhando para o aluno como ser pensante e capaz de compreender seu processo de alfabetização como forma de libertação da sociedade opressora. Segundo Freire (1981, p. 35),

Quanto mais for levado a refletir sobre sua situcionalidade, sobre seu enraizamento espaço temporal, mais "emergerá" dela conscientemente "carregado" de compromisso com sua realidade, da qual, porque é sujeito, não deve ser simples espectador, mas deve intervir cada vez mais.

Isso quer dizer que o estudante não deve estar na escola apenas para ouvir e aceitar os dizeres do educador, mas também para participar das aulas e dialogar com os educadores acerca de suas vivências, porque "é na inclusão do ser, que se sabe como tal, que se funda a educação como processo permanente. Mulheres e homens se tornam educáveis na medida em que se reconhecem inacabados" (Freire, 1996, p. 24).

Dessa forma, a partir do momento em que o sujeito adulto se vê na necessidade de aprender pode procurar na EJA a alfabetização, tendo sempre em mente que a educação formal é capaz de dialogar com suas experiências. Sem dúvida, essa atitude transformará para melhor o processo de ensino-aprendizagem, já que as especificidades da alfabetização da EJA não se limitam a ensinar sílabas soltas ou o alfabeto, ou então utilizar metodologias usadas na educação fundamental anos iniciais. Tendo em vista o público atendido por essa modalidade de ensino é necessário utilizar a vivência e as experiências do aluno no processo de ensino por meio do diálogo, para que os alunos se sintam úteis e inseridos nas aulas. Além disso, essa forma de ensinar poderia ser um novo conteúdo,

[...] com que ajudaríamos o analfabeto, antes ainda de iniciar sua alfabetização, para conseguir a destruição da sua compreensão "mágica" e a construção duma compreensão crescentemente crítica, seria a do conceito antropológico de cultura, isto é, a distinção entre estes dois mundos: o da natureza e o da cultura; o papel ativo do homem na sua realidade e com a sua realidade; o sentido de mediação que tem a natureza para as relações e a comunicação dos homens; a cultura como o acréscimo que o homem faz ao mundo que não criou; a cultura como resultado de seu trabalho, de seu esforço criador e recria-dor; a dimensão humanista da cultura; a cultura como aquisição sistemática da experiência humana, como uma incorporação, por isso crítica e criadora, uma justa-posição de informações e descrições "doadas"; a democratização da cultura, que é uma dimensão da democratização fundamental, frente à problemática da aprendizagem da escrita e da leitura, seria, pois, como uma chave com a qual o analfabeto inicia sua 
introdução no mundo da comunicação escrita. Como ser no mundo e com o mundo. Em seu papel de sujeito e não de mero e permanente objeto (Freire, 1981, p. 40).

Assim, o autor enfatiza a importância de valorizar a cultura atrelada aos conhecimentos que o aluno adulto traz para a sala de aula e que na maioria das vezes não é valorizado pelo professor. Esse pensamento de Freire (1981) se estende a outros autores, como veremos a seguir nas considerações de Loiva Dreyer:

Para a realização de seu trabalho, o educador deveria saber ouvir o educando em suas experiências e através delas elaborar seu roteiro de ação, apresentando materiais que apresentassem sentido para a vida dos alfabetizandos, proporcionando a eles ricos momentos de reflexão, durante os círculos de cultura - nomenclatura utilizada por Freire para apresentar essa fase do método (Dreyer, 2011, p. 3591).

Sendo assim, o ensinar na EJA deve abranger o estudante e seu próprio conhecimento prévio, pois o aluno adulto já traz consigo uma bagagem de conhecimento de mundo e não se limita a apenas querer entender o básico da alfabetização. Ao considerar esses quesitos, o professor deve privilegiar um ensino em que o aluno possa entender um pouco mais do mundo afora, um mundo além da escola. Isso ajuda os estudantes da EJA a se tornarem sujeitos reflexivos e mostra que eles podem ser livres para pensarem e buscarem mais conhecimentos.

Isso quer dizer ainda que instigar o aluno também faz parte das especificidades da alfabetização. É preciso, pois, torná-lo interessado em saber os motivos de determinado ensinamento, de modo a instigá-los para se interessarem pelos porquês de determinada leitura ou escrita. Dialogar em sala de aula sobre essas especificações tornam o estudante mais interessado em compartilhar seus saberes externos, tornando o processo de alfabetização cada vez mais significativo.

É possível olhar para esse processo de alfabetização de adultos com um olhar construtivista de Piaget apud Azenha (2000), que ressalta que o conhecimento é adquirido de acordo com as interações sociais em seus devidos ambientes. Assim, o aluno constrói seu conhecimento em meio às experiências vivenciadas por ele. Lembramos novamente que o público da EJA já chega em sala de aula com conhecimento de vida prévio. Dessa forma, o ensino pode ser dialogado com as realidades de vida dos estudantes.

Muito do construtivismo se assemelha com os questionamentos apontados por Freire (1996) a respeito de como alfabetizar adultos. A construção ou o desenvolvimento do conhecimento a partir do meio onde o aluno é inserido sempre é considerado perante a visão e o pensamento dos autores. Por conta disso, Freire (1996) questionava: "Por que não discutir com os alunos a realidade concreta onde se deva associar a disciplina cujo conteúdo se ensina?", e mais: "Por que não estabelecer uma necessária intimidade entre os saberes curriculares fundamentais aos alunos e a experiência social que eles têm como indivíduos?" (Freire, 1996, p. 15).

Essas indagações permitem afirmarmos que o contexto de onde vêm os alunos da EJA pode acrescentar no desenvolvimento social e escolar do educando, uma vez que, trazendo sua vivência e associando suas atividades cotidianas à aula, em si, o discente trabalhará seu intelecto e o crescimento de seu pensamento crítico. Portanto, deixa-se de lado a ideia de cartilhas com junção e leitura de sílabas soltas, uma vez que essa metodologia em nada desperta o interesse do aluno em aprender, afinal, esse método é comum nas séries iniciais quando a criança ainda é ensinada a decorar códigos básicos.

Contrário a isso, o processo de alfabetização na EJA pode abranger diversas estratégias de ensino para que o sujeito que a busca possa compreender a educação como uma maneira prazerosa de aprender, como afirma Dreyer: "Dessa forma, o objetivo da alfabetização de adultos é promover a conscientização acerca dos problemas cotidianos, a compreensão do mundo e o conhecimento da realidade social" (Dreyer, 2011, p. 395). Ensinar o aluno da EJA utilizando sua realidade diária ainda é a mais concreta e correta forma de inseri-lo na educação. Isso deixa claro que a familiaridade deve ser um dos pontos altos do professor para com a realidade do seu aluno. 
Enfim, a luta por uma educação de qualidade continua. Dentro do movimento da EJA as mudanças para alfabetizar o aluno devem ser constantes e perpassa pelo conhecer, entender e trazer para dentro do contexto escolar a vivência do aluno. É acreditar no seu potencial de capacidade de desenvolvimento de intelecto, além de promover a busca pelo crescimento educacional dos estudantes. Por conseguinte, é preciso ter em mente que o correto é acabar com os analfabetismos escolar e social, mas para isso é necessário entender o analfabeto e incentivar a sua permanência na escola.

\section{Alfabetização e Letramento na EJA}

Atualmente, ensinar a ler e escrever, isto é, alfabetizar turmas de EJA em escolas campesinas tornou-se um dos grandes desafios em todo o país. Esses desafios se encontram principalmente na metodologia de ensino utilizada pelo professor, que não pode ser a mesma adotada na educação infantil, uma vez que os alunos de EJA possuem famílias, trabalho, e buscam na "escola um lugar para satisfazer suas necessidades particulares, para integrar-se à sociedade letrada, da qual não pode participar plenamente quando não domina a leitura e a escrita" (Strelhow, 2010, p. 50).

De acordo com a Lei ${ }^{\circ}$ 9.394/96, é preciso que o professor das turmas da EJA adote estratégias e métodos de ensino que atendam aos interesses e às condições de vida (família e de trabalho) dos alunos (Brasil, 1996). Nessa linha de pensamento Moretto (2011, p. 104) ressalta que:

[...] é preciso que o professor conheça as características psicossociais e cognitivas de seus alunos. Ele precisa ter sensibilidade e fundamentação necessárias para detectar o contexto de vivência de seus alunos e com isso saber ancorar os novos conhecimentos propostos pela escola. Assim, precisa identificar, analisar e compreender as características de desenvolvimento psicológico e social deles para que seu ensino seja eficiente e eficaz. Assim, conhecendo suas realidades, poderá usar uma linguagem adequada e contextualizada.

Em outras palavras, é a partir do conhecimento das características dos alunos que o professor pode pensar novas formas de ensinar os conteúdos para os jovens e adultos que residem no campo. Segundo Silva et al. (2017, p. 8), uma forma atualmente discutida como "instrumento de elevação da capacidade de apropriação dos conhecimentos historicamente acumulados" é a alfabetização por meio do letramento, isto é, alfabetizar letrando. Ainda para Silva et al. (2017, p. 8),

[...] o letramento, apesar de ser um termo relativamente novo a ser introduzido na agenda das escolas, faz parte de todo um processo de constituição e orientação para as políticas públicas e traz subsídios para a estruturação de uma 'forma e conteúdo' do processo de ensino e aprendizagem dos níveis de alfabetização.

Essa forma de ensinar baseada no letramento surge na década de 80 com o objetivo de "buscar alternativas e de qualificar o ensino da leitura e da escrita nos países chamados de 'terceiro mundo' como é o caso da América Latina, os quais representam os maiores índices de analfabetos e analfabetos funcionais" (Silva et al., 2017, p. 11).

Mas o que é alfabetização e letramento? A estudiosa no assunto, Magda Soares, explica alguns conceitos. Segundo a autora, explicar o que vem a ser alfabetização e letramento não é tarefa fácil, pois primeiro precisamos entender o que é Alfabetização.

Soares (2016) ressalta que o processo de alfabetização se relaciona com a apropriação da escrita e da leitura: "alfabetizar significa adquirir a habilidade de decodificar a língua oral em língua escrita [...]. A alfabetização seria um processo de representação de fonemas em grafemas (escrever) e de grafemas em fonemas" (Soares, 2016, p. 15).

Kleiman (2008, p. 18) menciona que "[...] podemos definir hoje o letramento como um conjunto de práticas sociais que usam a escrita, como sistema simbólico e como tecnologia, em contextos específicos, para objetivos específicos". Desse modo, o conceito da autora enfatiza os aspectos social e utilitário do letramento. 
As práticas específicas da escola, que forneciam o parâmetro de prática social segundo a qual o letramento era definido, e segundo a qual os sujeitos eram classificados ao longo da dicotomia alfabetizada ou não alfabetizada, passam a ser, em função dessa definição, apenas um tipo de prática - de fato, dominante - que desenvolve alguns tipos de habilidades, mas não outros, e que determina uma forma de utilizar o conhecimento sobre a escrita (Kleiman, 2008, p. 19).

A partir dessa perspectiva do letramento, a autora deixa em evidência que a escola destaca apenas algumas práticas ligadas à escrita e ao uso da escrita. Assim, fora do ambiente escolar outros usos e práticas ligados à escrita são vivenciados e muitas vezes não são valorizados por ela.

Diante disso, Kleiman (2008, p. 20) assegura que o "[...] fenômeno do letramento extrapola o mundo da escrita tal qual ele é concebido pelas instituições que se encarregam de introduzir formalmente os sujeitos no mundo da escrita". Dessa forma e de acordo com o que já foi explicitado pela autora, letramento seria um conjunto de práticas com objetivos específicos e em contextos específicos, que envolvem a escrita e a leitura. A escola, por sua vez, seria apenas uma agência de letramento, dentre várias outras, e realizaria apenas algumas práticas de letramento.

\section{Metodologia}

A pesquisa se caracteriza como um estudo de caso, segundo princípios e conceitos discutidos por Yin (2015), com abordagem qualitativa. O estudo de caso investiga determinado fato dentro de seu contexto da vida real, podendo ser utilizado quando se propõe a lidar com condições contextuais acreditando-se que elas poderiam ser altamente pertinentes ao seu fenômeno de estudo (Yin, 2015).

A pesquisa qualitativa, "tem o ambiente natural como fonte direta dos dados e o pesquisador como instrumentochave". Esse tipo de abordagem trabalha os dados buscando seu significado, tendo como base a percepção do fenômeno dentro do seu contexto. "O uso da descrição qualitativa procura captar não só a aparência do fenômeno como também suas essências, procurando explicar sua origem, relações e mudanças, e tentando intuir as consequências” (Triviños, 1987, p. 127). Ainda de acordo com o referido autor, é desejável que a pesquisa qualitativa tenha como característica a busca por

[...] uma espécie de representatividade do grupo maior dos sujeitos que participarão no estudo. Porém, não é, em geral, a preocupação dela a quantificação da amostragem. E, ao invés da aleatoriedade, decide intencionalmente, considerando uma série de condições (sujeitos que sejam essenciais, segundo o ponto de vista do investigador, para o esclarecimento do assunto em foco; facilidade para se encontrar com as pessoas; tempo do indivíduo para as entrevistas, etc.) (Triviños, 1987, p. 132).

Desse modo, buscamos aplicar um questionário com questões semiabertas destinado ao professor que trabalha com a turma de EJA e à direção da escola. O objetivo consistiu em analisar as reflexões acerca das percepções e práticas de alfabetização adotadas por esses profissionais na Escola Santo Antônio, situada no Rio Bacuri, em Abaetetuba (PA).

Para Triviños (1987, p. 146), na pesquisa qualitativa "a entrevista semiestruturada é um dos principais meios que tem o investigador para realizar a Coleta de Dados". Esse tipo de técnica "valoriza a presença do investigador, oferece todas as perspectivas possíveis para que o informante alcance a liberdade e a espontaneidade necessárias, enriquecendo a investigação" (Triviños, 1987, p. 146).

Durante a coleta de dados, foram realizadas as entrevistas mediante um roteiro semiestruturado. A gravação foi feita em um aparelho celular, em função de deixar os entrevistados opinarem livremente. Essas entrevistas aconteceram em clima de conversa informal, o que enriqueceu a coleta de dados mesmo em assuntos que não pareciam ligados ao foco da pesquisa.

Nas análises de dados o professor será identificado como PROFESSOR-EJA e a gestora como DIRETORA para facilitar as identificações. A partir da transcrição e leitura das entrevistas foram selecionados os discursos dos entrevistados de 
acordo com os pontos de interesse para a pesquisa. Então, "a entrevista pode ser um meio do qual precisamos para obter as certezas que nos permite avançar em nossas investigações" (Trivinos, 1987, p. 137).

\section{Resultados e Discussão}

Compreender quais são as práticas de alfabetização e letramento adotados na Escola Municipal de Educação Infantil e Ensino Fundamental Santo Antônio, no rio Bacuri, zona rural do município de Abaetetuba (PA), é essencial para entender vários percalços que ocorrem no processo de alfabetização da EJA. Tendo em vista essa ideia, a análise foi feita a partir das categorias extraídas dos discursos do professor da EJA e da diretora responsável pela escola. As categorias selecionadas foram: alfabetização e letramento, desafios no processo de ensinar, metodologias, estratégias para evitar a evasão escolar e aprendizagem e educação como emancipação. Para embasar teoricamente a discussão, fez-se necessário uma busca de informações aos principais autores que envolvem esses procedimentos.

Sabe-se que para alfabetizar na Educação de Jovens e Adultos, conforme Barbosa (2015), é preciso o considerar não apenas os fatores da educação formal, como ler e escrever, mas, principalmente, outras especificidades observadas no dia a dia da sala de aula, como: o cansaço dos alunos após um dia intenso de trabalho, as dificuldades de enxergarem devido a problemas de visão, as diversas preocupações do alunado com relação ao ambiente familiar perturbador e conflituoso em que vivem, tais como: droga, alcoolismo e ciúme, os problemas financeiros, entre outros empecilhos que interferem na aprendizagem. De acordo com o autor, é nesse contexto que se apresenta o verdadeiro

desafio para o educador em fazer com que os educandos se sintam em um ambiente agradável, onde esqueçam por algumas horas os problemas do dia-a-dia e se voltem para um diálogo onde se estabeleça um ambiente agradável e assim, ele tenha vontade de permanecer e aprender (Barbosa, 2015, p. 25).

Enfim, "a escola também deve estar preparada para os desafios enfrentados ao alfabetizar os jovens ou adultos, visto que os métodos pedagógicos precisam ser diferenciados e dentro da realidade dos educandos", como observa Barbosa (2015 p. 25). Em relação aos questionamentos sobre alfabetização e letramento, identificou-se que o professor da EJA define alfabetização de forma precisa, porém apresenta dúvidas sobre o que vem a ser o letramento, definindo o termo de forma vaga, como podemos ver a seguir:

Alfabetização é o aluno saber ler e escrever [...], quando o aluno já sabe escrever sozinho seu nome completo sem olhar no modelo, escreve palavras, textos... aí nós falamos que ele já está alfabetizado. Agora como é alfabetizar esse aluno letrando, é quando eu, professor ensino de uma forma diferente (PROFESSOR-EJA).

Com base nos discursos do professor, alfabetizar é mais que aprender os códigos linguísticos e saber as habilidades que serão necessárias para a decodificação dos fonemas em grafemas e para a decodificação de grafemas em fonemas, ou seja, o domínio do sistema de leitura e escrita. É assim também que a diretora da escola compreende o conceito de alfabetizar:

Acredito que alfabetização é estar alfabetizado [...] já saber ler e escrever, fazer as operações de matemática, escrever com autonomia. Acredito que resumidamente seja isso (DIRETORA).

Acerca do assunto, Oliveira (2015) esclarece que tanto a alfabetização como o letramento são termos que se complementam, porque "estão inter-relacionados, pois um facilita a aquisição e a importância do outro. Compreender a função social da linguagem é ter um bom domínio do uso da leitura e da escrita, é condição para se ter um bom nível de letramento" 
(Oliveira, 2015 p. 13). Isso sinaliza que Soares (2003 p. 91) define que tanto a alfabetização como o letramento possuem interrelação entre eles.

\begin{abstract}
Alfabetização- tomando-se a palavra em seu sentido próprio - como o processo de aquisição da "tecnologia da escrita", isto é, do conjunto de técnicas-procedimentos, habilidades - necessárias para a prática da leitura e da escrita: as habilidades de codificação de fonemas em grafemas e de decodificação de grafemas em fonemas, isto é, o domínio do sistema da escrita (alfabético, ortográfico) [...] em síntese: alfabetização é o processo pelo qual se adquire o domínio de um código e das habilidades de utilizá-lo para ler e escrever, ou seja, domínio da tecnologia - do conjunto de técnicas - para exercer a arte e ciência da escrita.
\end{abstract}

Diante da posição da autora, pode-se pontuar que alfabetizar é o processo que estar ligado à produção do conhecimento. O termo está inclusive ligado a outras áreas, como: "alfabetização musical, alfabetização matemática, alfabetização em informática, aquisição da leitura e da escrita formal” (Oliveira, 2015, p. 13). Letramento, para Soares (2003, p. 91-92), é

O exercício efetivo e competente da tecnologia da escrita [...] que implica habilidades várias, tais como: capacidade de ler e escrever para atingir denominados objetivos - para informar ou informar-se, para interagir com outros, para imergir no imaginário, no estético, para ampliar conhecimentos para seduzir ou induzir, para divertir-se, para orientase, para apoio da memória, para catarse [...] habilidade de interpretar e produzir diferentes tipos e gêneros de textos, habilidades de orientar-se pelos protocolos de leitura que marcam o texto ou de lançar mão desses protocolos, ao escrever, atitude de inserção efetiva no mundo da escrita, tendo interesse e prazer em ler e escrever, sabendo utilizar a escrita para encontrar ou fornecer informações e conhecimentos escrevendo ou lendo de forma diferenciada, segundo as circunstância, os objetivos, o interlocutor.

Em relação à alfabetização e ao letramento, Soares (2003) ressalta que essa relação pode socorrer em base diferente do que a alfabetização em seu sentido estrito. A pesquisadora explica que

\begin{abstract}
Alfabetização e letramento são, pois, processos distintos de natureza essencialmente diferente. Entretanto, são interdependentes e mesmo indissociável. A alfabetização -a aquisição da tecnologia da escrita - não procede e não é pré-requisito para o letramento, isto é, para a participação em práticas sociais de escrita, tanto assim que analfabetos podem ter um certo nível de letramento, não tendo adquirido a tecnologia da escrita, utiliza-se de quem a tem para fazer uso da leitura e de escrita, além disso, na concepção psicogenética de alfabetização que vigora atualmente a tecnologia da escrita é aprendida não como em concepções anteriores, com textos construídos artificialmente para aquisição das técnicas de leitura e de escrita, mas através de atividades de letramento, isto é, de leitura e produção de textos reais, de práticas sociais de leitura e de escrita (Soares, 2003, p. 92).
\end{abstract}

No quesito sobre os desafios de ensinar na Educação de Jovens e Adultos, o professor relata:

Os desafios são muitos de trabalhar na EJA, mas com jeito eu procuro fazer o trabalho tudo certo. Eu procuro a melhor forma de trabalhar que agrade o aluno, né? Porque a maioria são adultos, né? Pessoas que estão cansadas do trabalho [...] aí eu trabalhava antes a partir de uma da tarde, aí alguns alunos pediram para mudar o horário, porque tinham alunos que uma da tarde, duas horas, eles ainda estavam trabalhando, tirando açaí, fazendo seus afazeres, né? Aí eu conversei com a diretora e também com a coordenação da EJA pra mudar o horário. Agora começa cinco da tarde para facilitar, né? (PROFESSOR EJA).

Diante do relato do professor, pode-se perceber que são diversos os desafios enfrentados no processo de ensino e aprendizagem da Educação de Jovens e Adultos da Escola Santo Antônio. Os desafios vão desde os horários das aulas, que precisam ser adaptados para o atendimento dos alunos que trabalham, passando pelo local em que são desenvolvidas as aulas, que atualmente acontece em uma residência anexa à escola. Isso compromete a privacidade de ensinar, que é interrompida. 
Ademais, a falta de pessoal de apoio para ajudar o professor na arte de educar, como serventes e coordenação pedagógica é outro empecilho.

Outro desafio é que as aulas da EJA acontecem em uma casa de uma senhora da comunidade, que é estudante da EJA. Ela doou o espaço para que as aulas acontecessem, né? Mas assim, fica um pouco difícil, porque uma casa não é igual à escola, né? Eu preciso de privacidade, né, pra dá aula?! [...]. A aula acontece aqui nessa casa por causa dos alunos que a maioria mora aqui próximo [...]. Outra coisa é que eu trabalho sozinho, não tem outro funcionário pra ajudar. É a minha sobrinha que faz e eu levo para o anexo (PROFESSOR EJA).

Segundo Porcaro (2011, p. 41), além desses desafios, a EJA também enfrenta "a heterogeneidade, a evasão, a juvenilização das turmas, a falta de materiais didáticos específicos, a baixa autoestima dos educandos, a rigidez institucional". A autora destaca que, em todas essas situações, os "educadores apontam que vão buscando caminhos alternativos que favoreçam o processo de ensino como criações próprias de cada um diante das circunstâncias que vão enfrentando" (Porcaro, 2011, p. 41).

No decorrer da entrevista o professor relata que em sua prática profissional cria estratégias diversificadas para efetivar o sucesso do processo de aprendizagem, bem como para evitar a evasão escolar dos alunos da EJA.

A EJA não é só escrever e ler, encher o quadro lá e deixar o aluno copiar tudo aquilo, não. Eu vejo que a EJA ela tem que ter criatividade que aqui eu uso, né? Aí eu vou de acordo com as realidades, com as situações. Por exemplo, a gente não passa nenhuma data comemorativa sem fazer alguma coisa, a época da Páscoa, o Dia das Mães, o Sete de Setembro, o Natal. Aí eu passo todas as comemorações, todas as datas comemorativas aí eu... aí reúne com todos os alunos, vamos ver o que eles vão dar, se é bolo, se é cachorro-quente, se é churrasco, aí a gente faz a programação. Por exemplo, no mês de setembro eu os levei para o campo, fiz brincadeiras no campo, levei coisas para a gente comer lá... Isso é uma diversão, uma atividade diferenciada, não é só ler e escrever, né? Eu passo muito essas atividades diferenciadas (PROFESSOR EJA).

Como se pode perceber, as palavras criatividade, diversão e atividade diferenciada são categorias-chaves no discurso do professor. Ele as utiliza no processo de ensino e aprendizagem de seus alunos. Isso demostra sua dedicação e seu comprometimento em oferecer uma educação significativa para os alunos da EJA. É necessário observar que essa forma de ensinar vai de encontro com a educação tradicional - que Paulo Freire denomina de bancária, em que há um depósito de conhecimento. Segundo Freire (2005), a concepção bancária nega o diálogo entre professor e alunos, à medida que na prática pedagógica prevalecem poucas palavras, já que "o educador é o que diz a palavra; os educandos, os que a escutam docilmente; o educador é o que disciplina; os educandos, os disciplinados" (Freire, 2005, p. 68).

\section{Conclusão}

O objetivo desta pesquisa foi desenvolver uma investigação sobre as percepções e práticas de alfabetização adotados na Escola Municipal Santo Antônio, Rio Bacuri, zona rural do município de Abaetetuba. Considerando as posições dos teóricos frente à temática em estudo foi possível compreender que a alfabetizar letrando em turmas de Educação de Jovens e Adultos não é tarefa fácil, porque para realizar essa prática o professor precisa compreender duas categorias essenciais: a alfabetização e o letramento. Assim conseguirá desenvolver sua prática pedagógica em sala de aula com sucesso.

A partir da concepção de vários autores, como Magda Soares, alfabetização e letramento são processos simultâneos, indissociáveis, que ocorrem no início da escrita alfabética dos adultos e das crianças que ainda não foram alfabetizados. De acordo com a entrevista do professor, seus conhecimentos ainda precisam ser revistos, pois ele compreende o processo de alfabetização e letramento ainda de forma vaga imprecisa, apresentando dúvidas sobre essas categorias. 
Em relação aos desafios de ensinar na Educação de Jovens e Adultos, tanto o professor como a diretora da escola ressaltam que são diversos e vão desde os horários das aulas, que não correspondem com a disponibilidade dos alunos, até a falta de espaço para o desenvolvimento das aulas, bem como a falta de profissionais na escola, como a coordenação pedagógica e os serventes, pois o que se percebe é que o professor da EJA trabalha sozinho, acumulando funções.

No decorrer das entrevistas foi possível perceber ainda que apesar de todos esses e outros desafios que o professor enfrenta para desenvolver seu trabalho docente, ele cria e desenvolve diferentes estratégias para diversificar seu trabalho, contribuindo com o processo de ensino e aprendizagem dos alunos da EJA.

A entrevista do professor revelou inclusive que ele cria estratégias diversificadas para que o processo de aprendizagem ocorra com sucesso, bem como contribui para evitar a evasão escolar dos alunos da EJA da Escola Municipal de Educação Infantil e Ensino Fundamental Santo Antônio, na zona rural do município de Abaetetuba. No entanto, sabe-se que alfabetizar letrando é mais que criar estratégias, mas ter o conhecimento de todas as etapas desse processo educativo que, conforme Magda Soares, requer conhecimentos teóricos de variados gêneros do discurso como práticas de letramento para instrumentalizar o aprendiz sem subtrair dele seus conhecimentos prévios e valorosos para o processo de alfabetização.

Estudos dessa natureza precisam ser ampliados para outras turmas da EJA localizadas nas ilhas de Abaetetuba. Além de estudos sobre as políticas públicas de formação docente direcionadas para o público que trabalha com EJA nessa região.

\section{Referências}

Almeida, B., Antonio, C. A. \& Zanella, J. L. (Orgs.) (2008). Educação do Campo: um projeto de formação de educadores em debate. EDUNIOESTE.

Azenha, M. da G. (2000). Construtivismo: de Piaget a Emília Ferreiro. (7a ed.), Ática.

Barbosa, R. (2015). Os desafios da alfabetização na Educação de Jovens e Adultos. Faculdade de Educação - UAB/UNB/MEC/SECADI III Curso da Especialização em Educação na Diversidade e Cidadania com Ênfase em EJA, 2015.

Brasil. (1996) Lei das Diretrizes e Bases da Educação.

Braga, A. C. \& Mazzeu, F. J. C. (2017) O analfabetismo no Brasil: lições da históricas. Revista on line de Política e Gestão Educacional, 21 (1), 24-46. 10.22633/rpge.v21.n.1.2017.9986

Dalbosco, A. (2015). Processo de Ensino Aprendizagem na Educação de Jovens e Adultos - EJA. https://repositorio.ifsc.edu.br/handle/123456789/200 Acesso em 14 de junho, 2021,

Dreyer, L. (2011). Alfabetização: O olhar de Paulo Freire. X Congresso Nacional de Educação - EDUCERE, PUCPR.

Freire, P. (1981). Educação e Mudança. (12a ed.), Paz e Terra.

Freire, P. (1987). Pedagogia do Oprimido. (17a ed.), Paz e Terra.

Houaiss, A. \& Villar, M. de S. (2004). Dicionário Houaiss da Língua Portuguesa. Objetiva.

Kleiman, A. B. (2008). Modelos de letramento e as práticas de alfabetização na escola. In.: Kleiman, A. B. (Org.). Os Significados do Letramento: uma nova perspectiva sobre a prática social da escrita. Campinas: Mercado das Letras.

Luz, N. S., Oliveira, E. L. \& Leão, M. F. (2021). Tempo de colher, tempo de plantar: alfabeletrar na e pela vivência no campo. Research, Society and Development, 10 (7), 1-12. 10.33448/rsd-v10i7.16405

Moretto, V. P. (2011). Construtivismo: A produção do conhecimento em aula. Lamparina.

Oliveira, S. F. S. (2015). Alfabetização, Letramento e Educação de Jovens e Adultos (EJA): Caminhos e Descaminhos. Trabalho de Conclusão de Curso (Graduação em Pedagogia). Universidade Estadual da Paraíba, Centro de Educação. Campina Grande.

Perrenoud, P. (2000) Construir competências é virar as costas aos saberes? Revista Pátio, 11(03) 15-19.

Porcaro, R. C. (2011). Os desafios enfrentados pelo educador de jovens e adultos no desenvolvimento de seu trabalho docente. EccoS Revista Científica, (25), 39-57. https://www.redalyc.org/pdf/715/71521708003.pdf

Santos, M. I. A. \& Ribeiro, A. P. M. (2020). O ensino-aprendizagem na educação de jovens e adultos e a teoria da reprodução de Bourdieu. Research, Society and Development, 9 (3), 1-15. 10.33448/rsd-v9i3.2532

Silva, A. W. P., Dias, V. G. \& Paludo, C. (2017) Os Desafios Estratégicos da Alfabetização e Letramento na Formação de Professores da/na Educação do Campo. Momento: diálogos em educação. 26 (1) 96-117. 10.14295/momento.v26i1.5473 
Research, Society and Development, v. 10, n. 10, e567101019220, 2021

(CC BY 4.0) | ISSN 2525-3409 | DOI: http://dx.doi.org/10.33448/rsd-v10i10.19220

Soares, M. (2016). Alfabetização: a questão dos métodos. Contexto.

Soares, M. (2003). Alfabetização e Letramento. Contexto.

Strelhow, T.B. (2010). Breve História sobre a Educação de Jovens e Adultos no Brasil. Revista HISTEDBR On-line, 38, 49-59. 10.20396/rho.v10i38.8639689

Triviños, A.N.S. (1987) Introdução à Pesquisa em Ciências Sociais: a pesquisa qualitativa em educação. Atlas.

Yin, R.K. (2015). O estudo de caso. Bookman 